Janet $E$. Frantz, University of Southwestern Louisiana. "Pruning a State: A Study of Termination." \$1,500.

Judith Gentleman, State University of New York, Geneseo. "The National Action Party (PAN) and Political Change in Mexico." \$1,500.

Janet Martin. Bowdoin College. "Women Who Govern: An Examination of Presidential Appointments." \$1,500.

Michael Mitchell, Saint Peter's College.

"Redemocratization in Brazil." \$1,500.

Robert C. Oberst, Nebraska Wesleyan University. "Federal Responses to Ethnic Conflict." \$1,500.

H. V. Savitch, State University of New York, Purchase. "Politics, Policy and PostIndustrial Transformation." $\$ 1,500$.

Genie W. L. Stowers, University of Alabama at Birmingham. "Ethnic Political Transportation: The Integration of Cubans into the Miami Political System." $\$ 1,500$.

\section{Members Contribute to APSA's Endowed Fund}

The following persons have contributed $\$ 25$ or more to the APSA's Trust and Development Fund since January I, 1988:

Gabriel A. Almond

William I. Bacchus

Thomas C. Blaisdell, Jr.

Peter Bjornsson

Daniel S. Cheever

James W. Fesler

Frances L. Fung-Wai

Janice Hopper

Jack H. Mower

Burton B. Moyer, Jr.

Koichiro Oishi

C. H. Pritchett

Roberta Sigel

Aaron Wildavsky

\section{Annual Meeting}

\section{Policies and Deadlines}

Paper proposals and offers to appear as discussants or panel chairpersons must be submitted as early as possible. The deadline for receipt of submissions is December I, 1988. Proposals for whole panels are welcome, but persons with suggestions for panels should get their requests in early.

Please write directly to the appropriate section chairperson listed below. More general inquiries or suggestions may be addressed to:

Nelson W. Polsby, Department of Political Science, University of California, Berkeley, CA 94720; (415) 642-6323 (Program Chair).

Norinne Hessman or Ann Peyser, APSA, 1527 New Hampshire Avenue, NW, Washington, DC 20036; (202) 483-2512.

Prospective participants should be aware of two APSA Council policies:

(1) Acceptance of a proposal by the Program Committee obligates you to preregister (with appropriate fee) prior to June 1, 1989. If you fail to preregister, you will not be listed in the final program.

(2) Participants may appear on two (but no more than two) panels in any capacity-chairing a panel, acting as discussant or presenting a paper. This rule applies to APSA Program Committee panels, APSA Organized Section panels, APSA-Sponsored Committee panels, and Unaffiliated Group panels.

If you apply to several sections, please inform each section chairperson that this is a multiple application. Also, in that case, please notify the other section shairpersons as soon as you have accepted an invitation for participation in another section. 